\title{
Detection of mitochondrial coupling factor 6 in placental tissues from preeclamptic pregnancies and its influence on biological behavior of trophoblast cells
}

\author{
WANYU SONG, XUFENG SHI, KAN LIU, RANHONG LI, LEILEI NIU, LIJUN SU and HAIYING WU
}

Department of Gynecology and Obstetrics, Henan Provincial People's Hospital, Zhengzhou, Henan 450000, P.R. China

Received June 12, 2019; Accepted March 15, 2021

DOI: $10.3892 / \mathrm{etm} .2021 .10619$

\begin{abstract}
Increased levels of mitochondrial coupling factor 6 (CF6) are present in the peripheral blood of patients with preeclamptic pregnancies, and are particularly evident in cases of early-onset or severe preeclampsia. The present study examined the location and expression levels of CF6 in the placental tissue and its effect on the biological behavior of trophoblast cells. Placental tissue microarrays, including placental villous cytotrophoblast and extravillous cytotrophoblast microarrays, were used to detect the location and relative expression levels of CF6 in the placenta using immunohistochemistry. It was found that CF6 was expressed in both the normal and preeclamptic placenta, but its levels were higher in the preeclamptic tissues. In addition, the effects of the hypoxic environment on the biological behaviors of trophoblast cells were investigated in the JAR and JEG-3 cell lines. Following induction of hypoxia, the expression levels of CF6 were increased. Moreover, exogenous addition of human recombinant CF6 attenuated cell invasion, but exerted no effect on cell proliferation. At the molecular level, the expression levels of MMP-2 were decreased and were accompanied with a reduction in cell invasion following addition of exogenous CF6. In conclusion, the increased expression levels of CF6 and its effects in reducing the invasive abilities of trophoblast cells may be involved in the pathogenesis of severe preeclampsia.
\end{abstract}

Correspondence to: Dr Haiying Wu, Department of Gynecology and Obstetrics, Henan Provincial People's Hospital, 7 Weiwu Road, Zhengzhou, Henan 450000, P.R. China

E-mail: whysunnyzg@163.com

Abbreviations: CF6, coupling factor 6; EVCT, extravillous cytotrophoblast; RT-qPCR, reverse transcription-quantitative PCR; TMA, tissue microarray; VCT, villous cytotrophoblast

Key words: preeclampsia, placenta, coupling factor 6, trophoblast, tissue microarray analysis

\section{Introduction}

Preeclampsia is a pregnancy disorder in which hypertension coupled with proteinuria or other symptoms of organ damage are present after the 20th week of gestation (1). Increased morbidity and mortality in pregnant women occur due to the damage caused to the body systems, such as the circulatory, urinary and digestive systems (1); however, the only effective way to treat this condition is to detach the placenta. During pregnancy, various factors as sFlt-1 and sEng are released from the placenta into the mother's bloodstream that trigger spasms of systemic small vessels, ischemia of organs and ultimately can lead to systemic damage (1).

As a main component of the human placenta, trophoblast cells play an irreplaceable role in healthy pregnancies. The trophoblasts are located on the surface of the blastocyst. During adhesion of the late blastocyst to the endometrium, trophoblast cells begin to differentiate and invade the endometrium, the $1 / 3$ of the uterine muscle layer and the vascular system, which ensures a sufficient blood supply to the placenta, maintaining normal embryo development $(1,2)$. Previous studies have revealed that an invasive insufficiency of trophoblast cells can lead to the occurrence of preeclampsia $(3,4)$. Moreover, it has been shown that hypoxia can lead to an insufficiency in invasion in the trophoblast cells (1).

Previous pathological investigations of preeclampsia have indicated that trophoblast cells that are immersed in a hypoxic environment have a reduced invasive capacity (1). Coupling factor 6 (CF6), also known as ATP5J, is a component of ATP synthase, an energy converter that is further composed of two subunits, namely F0 and F1 (2). As a component of F0, CF6 is released into the extracellular fluid as a circulating peptide and is also located on the membrane of various cells, such as endothelial cells in blood vessels $(2,5)$. Following binding to specific ligands, CF6 interrupts the vascular homeostasis through the activation of downstream signaling factors (5). After comparing normal pregnant women and normal non-pregnant women of childbearing age, a previous study demonstrated that the levels of CF6 were increased (1.5-3-fold) in the peripheral blood of the pregnant women with preeclampsia compared with those exhibiting normal pregnancies, with this result being particularly evident in patients with early-onset preeclampsia and severe preeclampsia (6). Therefore, it was hypothesized that a percentage of the CF6 levels detected in the peripheral blood 
circulation are secreted from the placenta. Previously, a search was performed for associated data in The Human Protein Atlas (http://www.proteinatlas.org/). The data demonstrated that CF6 is expressed in normal placental villous and extravillous trophoblast cells, although no information was present regarding its expression in abnormal cells, such as those noted in the preeclamptic placenta (7).

The present study aimed to determine the potential differences in CF6 expression between the normal and the preeclamptic placenta through the detection of CF6 protein using placental tissue microarrays (TMAs). The present findings indicated the clinical relevance of CF6 alterations in preeclampsia and may further expand existing knowledge concerning the biological functions of CF6.

\section{Materials and methods}

TMA materials. The placental TMAs, including placental villous cytotrophoblast (VCT) microarrays and extravillous cytotrophoblast (EVCT) microarrays, were previously successfully constructed and validated by our research group (8). The placental tissues collected for constructing TMAs were obtained from pregnant women (age range, 23-36-years old) recruited at the Third Affiliated Hospital of the Zhengzhou University (Zhengzhou, China) and Henan Provincial People's Hospital (Zhengzhou, China), from December 2007 to December 2010 (8). The employed diagnostic criteria of severe preeclamptic patients were defined based on the 'diagnosis and management of preeclampsia and eclampsia' guidelines (9). All of the pregnant women selected for the placental TMAs in the present study had singleton pregnancies, without chronic hypertension, diabetes, heart disease, liver disease or kidney disease. Deliveries were performed by cesarean section due to the scarred uterus, contracted pelvis, macrosomic infants or additional social reasons. The sample collection was approved by The Ethics Committee of Henan Provincial People's Hospital and The Ethics Committee of The Third Affiliated Hospital of the Zhengzhou University. The patients agreed to the use of their samples and each patient signed an informed consent form.

Immunohistochemistry of the placenta samples. Immunohistochemical staining. Immunohistochemistry was performed to assess the localization and expression of CF6 protein in placental TMA samples. The TMA samples were fixed with $1.4 \%$ paraformaldehyde and $0.1 \mathrm{~mol} / \mathrm{l}$ phosphoric acid buffer (pH 7.3) at $37^{\circ} \mathrm{C}$ for $24 \mathrm{~h}$. The thickness of a TMA slide was 4- $\mu \mathrm{m}$ (8). In brief, TMA slides were deparaffinized three times with xylene for 5 min each, and then dehydrated using 100, 90, 80 and $70 \%$ alcohol at room temperature. Antigens were retrieved by boiling TMA slides in $0.01 \mathrm{M}$ sodium citrate solution (Boster Biological Technology). The slides were then allowed to cool and treated with $3 \% \mathrm{H}_{2} \mathrm{O}_{2}$ for 10 min at room temperature to quench endogenous peroxidase activity. To reduce the non-specific background staining, the sections were blocked with fetal bovine serum albumin (cat. no. SA1052; Wuhan Boster Biological Technology, Ltd.) for $30 \mathrm{~min}$ at room temperature. Subsequently, the slides were probed with a rabbit anti-human CF6 polyclonal antibody (1:250; cat. no. ab224139; Abcam) in a humidified chamber at $4^{\circ} \mathrm{C}$ overnight. Following thorough washing in PBS, the staining was detected using an anti-rabbit immunohistochemistry kit (cat. no. SA1052; Wuhan Boster Biological Technology, Ltd.) and visualized using a DAB kit (Boster Biological Technology), both used according to the manufacturer's instructions. Finally, the slides were counterstained with hematoxylin (Boster Biological Technology).

Evaluation of staining. All images were obtained using an Olympus IX-71 inversion fluorescence microscope (Olympus Corporation) equipped with a DP-71 Digital Camera (Olympus Corporation). The images for analysis were captured using a digital camera using ImagePro 6.0 software (Media Cybernetics, Inc). The results were graded on a semiquantitative scale as follows: 0 (Negative), 1 (yellow), 2 (brown-yellow) and 3 (brown). The percentage of relevant positive cells was graded using the following scale: $0(<5 \%)$, $1(5-25 \%), 2$ (26-50\%), $3(51-75 \%)$ and $4(76-100 \%)$. The sum of the product of the two scores was regarded as the final score, which were graded by a four-point scale: 0 (Negative, -), $<4$ (weak staining, + ), 4-8 (moderate staining, ++ ) and $>8$ (intense staining, +++ ). The maximum score used was 12 . For each block, 3 high-power fields (magnification, $x 400$ ) were examined. The score was calculated by combining the staining intensity and the percentage of positive cells. The staining intensity was evaluated by two independent pathologists.

Cell culture and grouping. JAR and JEG-3 trophoblast cell lines were purchased from the American Type Culture Collection (ATCC) and were maintained in complete medium containing 90\% RPMI-1640 (without FBS; cat. no. 21870076; Gibco; Thermo Fisher Scientific, Inc.), 10\% FBS (cat. no. 11011-6123; Hangzhou Sijiqing Biological Engineering Materials Co., Ltd.), $100 \mathrm{U} / \mathrm{ml}$ of penicillin and $100 \mathrm{U} / \mathrm{ml}$ of streptomycin (cat. no. 15140-122; Gibco; Thermo Fisher Scientific, Inc) at $37^{\circ} \mathrm{C}$ in a humidified atmosphere with $5 \% \mathrm{CO}_{2}$. Following analysis of the growth curves of the two cell lines, cells in the exponential phase were seeded into a 6-well cell culture plate containing $2 \mathrm{ml}$ of complete medium at a density of $1.5 \times 10^{6}$ cells/well overnight until $60-70 \%$ confluence was reached. The following morning, the cells were divided into three groups: Control, hypoxia and CF6 stimulation group.

The hypoxic cellular model was established by adding a solution of $\mathrm{CoCl}_{2}$ to the cell culture medium as previously described (9). The final concentration of $\mathrm{CoCl}_{2}$ used was $200 \mu \mathrm{M}$ and the cells were incubated for an additional $24 \mathrm{~h}$. The hypoxic cellular model was deemed successful by detecting the protein expression levels of hypoxia-inducible factor $1 \alpha(\mathrm{HIF}-1 \alpha)$ of the cells using western blotting.

The CF6 stimulation group contained cells incubated in the complete medium that were mixed with exogenous human recombinant CF6 protein (Abcam) for $24 \mathrm{~h}$. The final concentration of CF6 was $0.1 \mu \mathrm{M}$, based on previous studies $(10,11)$. Subsequently, the cell culture medium was prepared and total RNA and protein levels from the cells were obtained for further use.

Enzyme-linked immunosorbent assay (ELISA). ELISA was performed to examine the cell medium concentration 
of CF6 in the hypoxia and control groups using the Human coupling factor 6 (CF6) kit (cat. no. CSB-E13880h; CUSABIO Technology LLC) according to the manufacturer's instructions. The optical density (OD) value was measured at $450 \mathrm{~nm}$ within 5 min following termination of the reaction using a Microplate Reader-K3 (Thermo Fisher Scientific, Inc.). The concentration of CF6 was calculated based on the resultant standard curve. The measurement range was 3.12-200 ng/ml.

Reverse transcription-quantitative PCR (RT-qPCR). RT-qPCR was performed to determine the transcriptional level of CF6 mRNA in the trophoblast cells in the hypoxia group and MMP mRNA expression in the CF6 stimulation group. The cells in the various groups were washed with PBS gently and collected. The total RNA was extracted from the placental tissues using the Trigol reagent (cat. no. NEP019-1; Beijing Dingguo Changsheng Biotechnology Co., Ltd.) according to the manufacturer's recommendations. Total RNA was then quantified using an ultraviolet spectrophotometer at $260 \mathrm{~nm}$. The RNA integrity was evaluated by agarose gel electrophoresis in order to determine the ratio of $28 \mathrm{~S} / 18 \mathrm{~S}$ rRNA in each sample. A total of $1 \mu \mathrm{g}$ RNA from each sample was reverse-transcribed into cDNA using a ReverTra Ace qPCR RT kit (Toyobo Life Science) at $95^{\circ} \mathrm{C}$ and qPCR analysis of CF6 was performed using Realtime PCR Master Mix (Toyobo Life Science). The human $\beta$-actin gene was used as an internal control for normalization of the mRNA amount. The sequences of the primers were as follows: CF6 forward, 5'-GCGACAGACATC TGGAGGAC-3' and reverse, 5'-GCCTGGGGTTTTTCG ATGAC-3'; MMP-2 forward, 5'-ACCAGATCACATACAGGA TC-3' and reverse, 5'-CTCTCCATCATGGATTCGAG-3'; MMP-9 forward, 5'-AGATGCGTGGAGAGTCGAAATC-3' and reverse, 5' GGTTCGCATGGCCTTCAGT-3'; and $\beta$-actin forward, 5'-CAGCAAGTGGGAAGGTGTAATCC-3' and reverse, 5'-CCCATTCTATCATCAACGGGTACAA-3'. All primers were designed and synthesized by Sangon Biotech Co., Ltd. RT-qPCR was performed in a final volume of $20 \mu \mathrm{l}$ and the samples were run in triplicate. As a negative control for all reactions, preparations lacking RNA were used in the place of cDNA. The reference gene was $\beta$-actin. PCR amplification was conducted via the following steps: Initial denaturation at $95^{\circ} \mathrm{C}$ for $1 \mathrm{~min}$, followed by 40 cycles at $95^{\circ} \mathrm{C}$ for $15 \mathrm{sec}$ and $60^{\circ} \mathrm{C}$ for $1 \mathrm{~min}$. The comparative method $2^{-\Delta \Delta \mathrm{Cq}}$ was used for the relative quantification of $\mathrm{CF} 6$ and MMP transcription in the various treatment groups (12).

Western blot analysis. Western blotting was performed to determine the protein expression levels of CF6, MMP enzymes and HIF-1 $\alpha$ in the various treatment groups. The cells were directly homogenized on ice using RIPA buffer containing a protease inhibitor cocktail (Beijing Solarbio Science \& Technology Co., Ltd.). The total protein concentration was determined using BCA assays (Beijing Solarbio Science \& Technology Co., Ltd.). Following quantification, each of the samples, containing $80 \mu \mathrm{g}$ of protein, was separated via $15 \%$ SDS-PAGE and subsequently electrophoretically transferred to nitrocellulose membranes. Following blocking with 5\% nonfat milk in $0.05 \%$ TBS-Tween-20 (TBST) at room temperature for $1 \mathrm{~h}$, the membranes were subsequently incubated with primary antibodies at $4^{\circ} \mathrm{C}$ overnight. The following antibodies were used: $\beta$-actin (1:4,000; cat. no. ab6302; Abcam;), CF6 (1:500; cat. no. ab224139, Abcam), MMP-2 (1:1,000; cat. no. ab92536; Abcam), MMP-9 (1:1,000; cat. no. ab76003; Abcam) and HIF-1 $\alpha$ (1:500; cat. no. BA0912-2, Wuhan Boster Biological Technology, Ltd.). The following day, the membranes were incubated with the horseradish peroxidase-conjugated goat anti-mouse immunoglobulin (1:5,000; cat. no. 926-32210) and goat anti-rabbit immunoglobulin (1:5,000; cat. no. 926-68021) (both LI-COR Biosciences) as the secondary antibodies for $2 \mathrm{~h}$ at room temperature in the dark. The membranes were washed with TBST, scanned and the protein bands were observed using an Odyssey infrared scanner (LI-COR Biosciences). The relative density of the proteins of interest was used for the relative quantification of expression.

MTT assay. An MTT assay was performed to determine the cell viability in the CF6 stimulation group. Following digestion of the cells with trypsin, the cells in the logarithmic phase were resuspended with complete culture medium and were seeded in 96-well plates. The cell concentration was adjusted to $2.5 \times 10^{3} / \mathrm{ml}$ before cell adherence. The medium in the wells of the experimental group was changed to complete medium and $0.1 \mu \mathrm{M} \mathrm{CF} 6$ was added. The cells were then incubated in a cell incubator for observation for $6,12,18$ and $24 \mathrm{~h}$. Furthermore, $50 \mu \mathrm{l}$ MTT solution ( $5 \mathrm{mg} / \mathrm{ml}$; Beijing Dingguo Changsheng Biotechnology Co., Ltd.) was added into each well. The medium was removed following $4 \mathrm{~h}$ of incubation and $200 \mu \mathrm{l}$ DMSO was added into each well to terminate the reaction. Finally, the OD value of each well was measured at $570 \mathrm{~nm}$ and the curve indicated the cell proliferation at the 24-h time point.

Transwell assay. A Transwell assay was performed to analyze the cell invasive ability under stimulation by exogenous CF6 according to the instructions of the manufacturer (Corning, Inc.). Briefly, Matrigel ${ }^{\mathrm{TM}}$ was diluted with cell culture medium (without FBS) at a ratio of 1:10 on the surface of the membrane in the upper chamber and incubated for 4-6 $\mathrm{h}$ in $37^{\circ} \mathrm{C}$. The Matrigel was solidified, and the cells $\left(2.5 \times 10^{5} / \mathrm{ml}\right)$ were trypsinized and resuspended with basic medium (without FBS), mixed with $0.1 \mu \mathrm{M}$ CF6 and seeded into the upper chamber of the 24-well plate. The lower chamber was filled with complete medium (750 $\mu \mathrm{l} /$ well), ensuring that the bottom surface of the membrane was in contact with the medium. Following incubation for $24 \mathrm{~h}$, the cells were fixed (3.7\% formaldehyde solution; room temperature; $2 \mathrm{~min}$ ), permeabilized (100\% methanol; room temperature; $15 \mathrm{~min}$ ) and stained (Giemsa dye; room temperature; $15 \mathrm{~min}$ ). The cells remaining in the upper chamber were carefully removed using a cotton swab, whereas the attached cells on the side of the membrane facing the lower chamber were counted under a light microscope (x400). At total of five fields were randomly counted in each chamber. The experiment was repeated three times.

Statistical analysis. Statistical analysis was conducted using SPSS 21.0 software (IBM Corp.). The normally distributed data were presented as the mean $\pm \mathrm{SD}$, whereas the data that was not normally distributed were presented as the median and interquartile range $\left[\mathrm{M}\left(\mathrm{P}_{25}-\mathrm{P}_{75}\right)\right]$. Comparisons 
Table I. Clinical characteristics of the pregnant women in the preeclampsia and normal groups.

\begin{tabular}{|c|c|c|c|c|c|c|}
\hline \multirow[b]{2}{*}{ Characteristic } & \multicolumn{3}{|c|}{ VCT TMA } & \multicolumn{3}{|c|}{ EVCT TMA } \\
\hline & Preeclampsia $(n=56)$ & Normal $(n=42)$ & P-value & Preeclampsia $(n=47)$ & Normal $(n=29)$ & P-value \\
\hline Age, years & $30.30 \pm 5.67$ & $28.43 \pm 3.90$ & 0.055 & $29.68 \pm 5.58$ & $28.87 \pm 3.71$ & 0.416 \\
\hline Systolic pressure, $\mathrm{mmHg}$ & $159.84 \pm 18.10$ & $105.00 \pm 12.26$ & $0.001^{\mathrm{a}}$ & $160.93 \pm 17.62$ & $111.06 \pm 10.34$ & $0.001^{\mathrm{a}}$ \\
\hline Diastolic pressure, $\mathrm{mmHg}$ & $109.67 \pm 8.68$ & $72.05 \pm 8.15$ & $0.001^{\mathrm{a}}$ & $105.16 \pm 11.94$ & $72.10 \pm 7.24$ & $0.001^{\mathrm{a}}$ \\
\hline Proteinuria, g/24 h & $8.29 \pm 6.50$ & 0.00 & $0.001^{\mathrm{a}}$ & $9.02 \pm 7.11$ & 0.00 & $0.001^{\mathrm{a}}$ \\
\hline Gestational age, weeks & $33.92 \pm 3.12$ & $39.02 \pm 1.38$ & $0.001^{\mathrm{a}}$ & $33.95 \pm 3.31$ & $38.97 \pm 1.19$ & $0.001^{\mathrm{a}}$ \\
\hline \multicolumn{7}{|l|}{ Preeclampsia } \\
\hline Early-onset & 41 & & & 38 & & \\
\hline Late-onset & 15 & & & 9 & & \\
\hline Mild & 8 & & & 3 & & \\
\hline Severe & 48 & & & 44 & & \\
\hline
\end{tabular}

${ }^{\mathrm{a}} \mathrm{P}<0.05$. EVCT, extravillous cytotrophoblast; TMA, tissue microarray; VCT, villous cytotrophoblast.

between the two groups were performed using the following tests: Unpaired Student's t-test, Mann-Whitney U test, Kruskal-Wallis or one-way ANOVA tests. Bonferroni tests were used as the post hoc tests for multiple comparisons. $\mathrm{P}<0.05$ was considered to indicate a statistically significant difference.

\section{Results}

Clinical characteristics of the pregnant women in the preeclampsia and normal control groups. To analyze the differences between the preeclampsia and normal control groups of pregnant women from whom placental tissues were collected and delivered, the present study analyzed the clinical characteristics of the pregnant women in both TMA groups. As seen in Table I, in placental VCT tissue microarray, the age of pregnant women in the PE group was 30.30 \pm 5.67-years-old, and that in the control group was $28.43 \pm 3.90$-years-old, with no statistically significant difference. The gestational weeks were $33.92 \pm 3.12$ and $39.02 \pm 1.38$ weeks, respectively, with statistically significant difference. In placental EVCT tissue microarray, the age of pregnant women in PE group was 29.68 \pm 5.58 -years-old, and that in the control group was $28.87 \pm 3.71$-years-old, with no statistically significant difference. The gestational weeks were 33.92 \pm 3.31 and $38.97 \pm 1.19$ weeks, respectively, with statistically significant difference.

CF6 protein expression is higher in the VCTs and EVCTs of patients with preeclampsia. To verify the location of CF6 in the placenta, immunohistochemistry was initially performed on VCT and EVCT TMAs, which included both preeclamptic and normal blocks. The results showed that in the VCT TMA, CF6 was expressed in the cytoplasm and on the plasma membrane of the cytotrophoblasts. CF6 displayed stronger staining intensity in the preeclamptic blocks than in the normal control blocks (Fig. 1A-D). The same results were obtained in the EVCT TMAs (Fig. 1E-H). The positive levels of immunostaining of CF6 in the preeclamptic VCT TMA reached 47/56 (83.9\%), which was significantly increased compared with the respective value in the normal VCT TMA (Table II). Among the preeclamptic VCT blocks, the positive rates in severe and early-onset preeclampsia were $42 / 48(87.5 \%)$ and $37 / 41(90.2 \%)$, respectively (Table II). The difference between the total positive percentages of the severe preeclampsia and the normal groups was statistically significant (Table II). In addition, the results showed that the positive percentage was higher in the early-onset preeclampsia group compared with in the normal group, although this difference was not statistically significant. Similar results were obtained from the EVCT TMA. The positive percentages of CF6 expression in preeclampsia, severe preeclampsia and early-onset preeclampsia were 39/47 (83.0\%), 36/44 (81.8\%), and $34 / 38(89.5 \%)$, respectively (Table III). These differences were statistically significant compared with those of the normal group (24/31, 77.4\%; Table III). The data of CF6 staining from the VCT and EVCT TMAs are presented in Tables II and III, respectively.

Establishment and evaluation of the hypoxic cellular model. According to previous studies, hypoxia is common in the placental microenvironment, and may influence the expression and release of CF6 $(6,13)$. In the present study, a hypoxic cellular model was established. However, due to the absence of a hypoxic incubator, $\mathrm{CoCl}_{2}(200 \mu \mathrm{M})$ was used for establishing the hypoxic environment. Increased expression levels of HIF-1 $\alpha$ in the cells indicated that hypoxia was induced. Using western blot assays, it was found that HIF-1 $\alpha$ protein expression levels were significantly upregulated in the cells incubated with $\mathrm{CoCl}_{2}$ for $24 \mathrm{~h}$ compared with in the normal cells (Fig. 2A and B). The results indicated that the hypoxic cellular model was successfully established.

Secretion and expression levels of CF6 are higher in hypoxic $J A R$ and JEG-3 cells. Following incubation of the cells under hypoxic conditions for $24 \mathrm{~h}$, the culture medium and cells were 
Table II. Immunostaining results for coupling factor 6 in villous cytotrophoblast tissue microarrays.

\begin{tabular}{|c|c|c|c|c|c|c|c|c|c|c|c|}
\hline \multirow[b]{2}{*}{ Group } & \multirow[b]{2}{*}{$\mathrm{N}$} & \multicolumn{2}{|c|}{ Negative } & \multicolumn{2}{|c|}{$\begin{array}{c}\text { Weak } \\
\text { staining }\end{array}$} & \multicolumn{2}{|c|}{$\begin{array}{l}\text { Moderate } \\
\text { staining }\end{array}$} & \multicolumn{2}{|c|}{$\begin{array}{l}\text { Intense } \\
\text { staining }\end{array}$} & \multirow[b]{2}{*}{ U } & \multirow[b]{2}{*}{ P-value } \\
\hline & & $\mathrm{N}$ & $\%$ & $\mathrm{~N}$ & $\%$ & $\mathrm{~N}$ & $\%$ & $\mathrm{~N}$ & $\%$ & & \\
\hline Preeclampsia & 56 & 9 & 16.1 & 11 & 19.6 & 15 & 26.8 & 21 & 37.5 & 560.5 & $<0.001^{\mathrm{a}}$ \\
\hline Severe & 48 & 6 & 12.5 & 9 & 18.8 & 13 & 27.1 & 20 & 41.7 & 708.5 & $0.014^{\mathrm{a}}$ \\
\hline Mild & 8 & 3 & 37.5 & 2 & 25 & 2 & 25 & 1 & 12.5 & & \\
\hline Early-onset & 41 & 4 & 9.8 & 6 & 14.6 & 11 & 26.8 & 20 & 48.8 & 706.0 & $0.152^{\mathrm{b}}$ \\
\hline Late-onset & 15 & 5 & 33.3 & 5 & 33.3 & 4 & 26.7 & 1 & 6.7 & & \\
\hline Normal & 42 & 12 & 28.6 & 7 & 16.7 & 14 & 33.3 & 9 & 21.4 & & \\
\hline
\end{tabular}

$\mathrm{N}$, number. ${ }^{\mathrm{a}} \mathrm{P}<0.05$ vs. Normal. ${ }^{\mathrm{b}} \mathrm{P}>0.05$ vs. Normal.

A

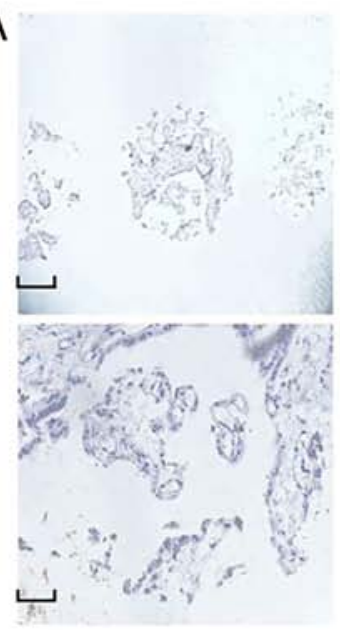

Negative

$(-)$

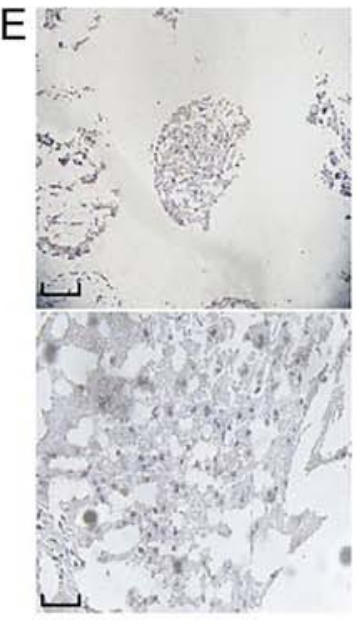

Negative

$(-)$
B

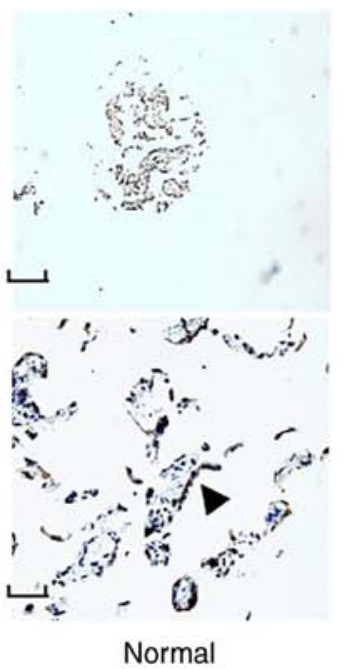

$(+)$
C

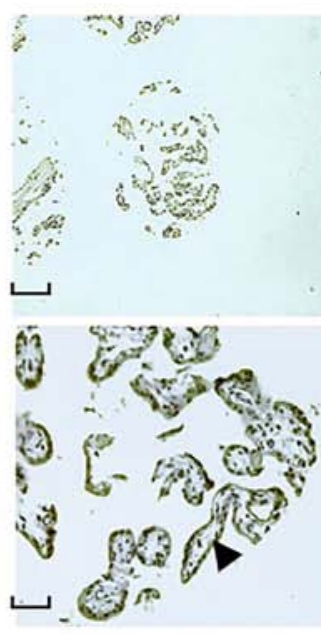

Early-onset preeclapsia

$(++)$

VCT TMA
$\mathrm{F}$

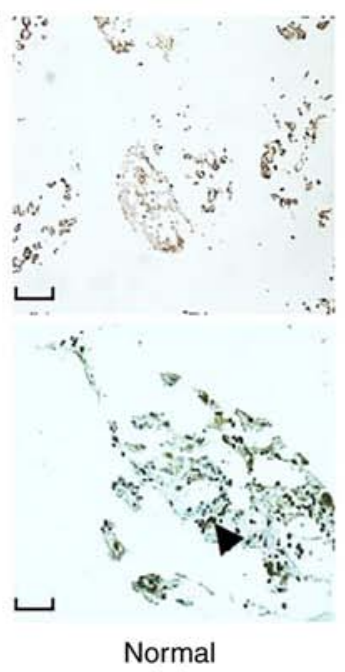

$(+)$

\section{EVCT TMA}

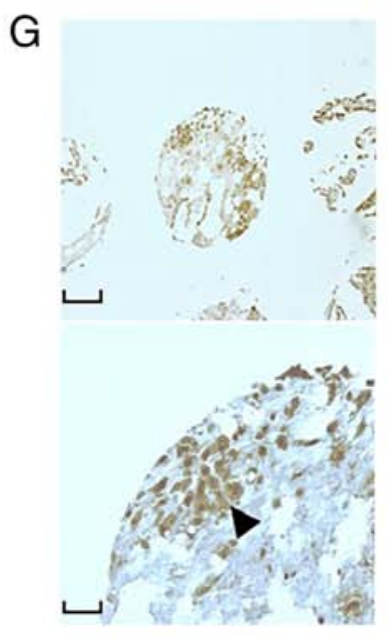

Early-onset preeclapsia

$(++)$

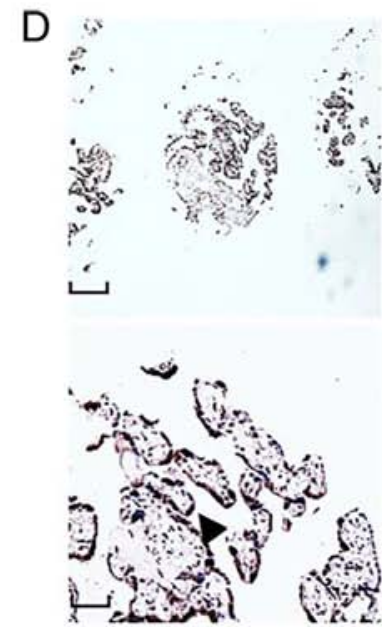

Severe preeclampsia $(+++)$

$\mathrm{H}$

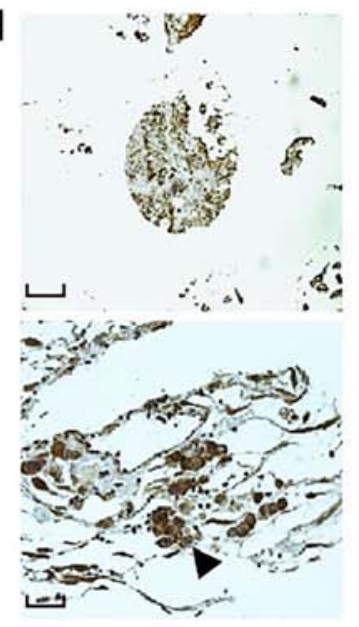

Severe preeclapsia $(+++)$

Figure 1. Representative results of CF6 immunohistochemistry staining in placental VCT and EVCT TMAs. Immunostaining of CF6 in VCT TMAs exhibiting (A) negative), (B) weak and (C) moderate staining, the latter in the early-onset group. (D) Intense staining in severe preeclampsia. Immunostaining of CF6 in EVCT TMAs exhibiting (E) negative, (F) weak and (G) moderate staining, the latter in the early-onset group. (H) Intense staining in severe preeclampsia. Magnification, x100 (top scale bar, $10 \mathrm{~mm}$ ) and x400 (bottom scale bar, $40 \mathrm{~mm}$ ) for each panel. Black arrows indicate positive expression of CF6. CF6, coupling factor 6; EVCT, extravillous cytotrophoblast; TMA, tissue microarray; VCT, villous cytotrophoblast. 
Table III. Immunostaining results for CF6 in extravillous cytotrophoblast tissue microarrays.

\begin{tabular}{|c|c|c|c|c|c|c|c|c|c|c|c|}
\hline \multirow[b]{2}{*}{ Group } & \multirow[b]{2}{*}{$\mathrm{N}$} & \multicolumn{2}{|c|}{ Negative } & \multicolumn{2}{|c|}{$\begin{array}{c}\text { Weak } \\
\text { staining }\end{array}$} & \multicolumn{2}{|c|}{$\begin{array}{l}\text { Moderate } \\
\text { staining }\end{array}$} & \multicolumn{2}{|c|}{$\begin{array}{l}\text { Intense } \\
\text { staining }\end{array}$} & \multirow[b]{2}{*}{$\mathrm{U}$} & \multirow[b]{2}{*}{ P-value } \\
\hline & & $\mathrm{N}$ & $\%$ & $\mathrm{~N}$ & $\%$ & $\mathrm{~N}$ & $\%$ & $\mathrm{~N}$ & $\%$ & & \\
\hline Preeclampsia & 47 & 8 & 17.0 & 10 & 21.3 & 14 & 29.8 & 15 & 31.9 & 104.0 & $<0.001^{\mathrm{a}}$ \\
\hline Severe & 44 & 8 & 18.2 & 8 & 18.2 & 14 & 31.8 & 14 & 31.8 & 208.0 & $<0.001^{\mathrm{a}}$ \\
\hline Mild & 3 & 0 & 0 & 2 & 66.7 & 0 & 0 & 1 & 33.3 & & \\
\hline Early-onset & 38 & 4 & 10.5 & 9 & 23.7 & 12 & 31.6 & 13 & 34.2 & 164.5 & $<0.001^{\mathrm{a}}$ \\
\hline Late-onset & 9 & 4 & 44.4 & 1 & 11.2 & 2 & 22.2 & 2 & 22.2 & & \\
\hline Normal & 31 & 7 & 24.1 & 7 & 24.1 & 9 & 31.0 & 8 & 27.6 & & \\
\hline
\end{tabular}

$\mathrm{N}$, number. ${ }^{\mathrm{P}}<0.05$ vs. Normal.
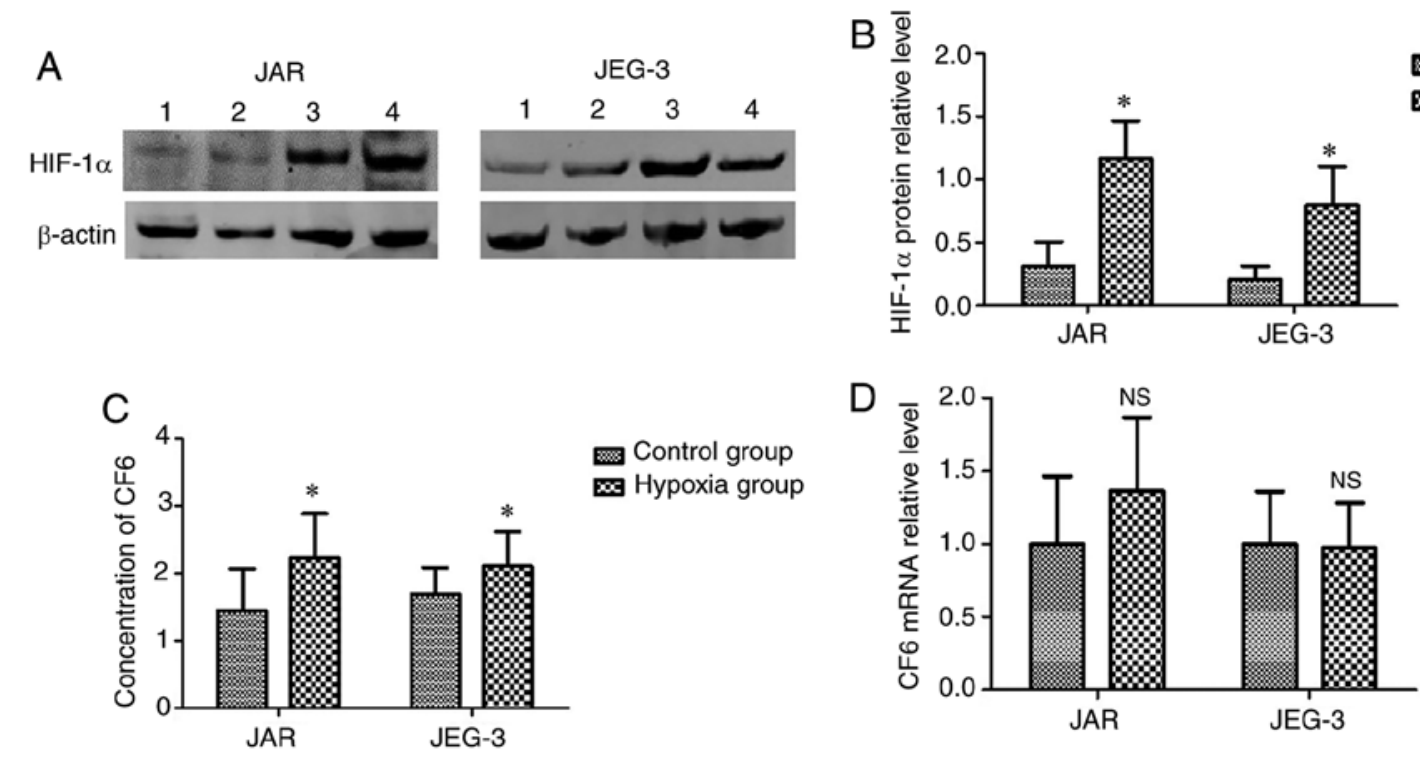

Control group Ex Hypoxia group

$\mathrm{F}$
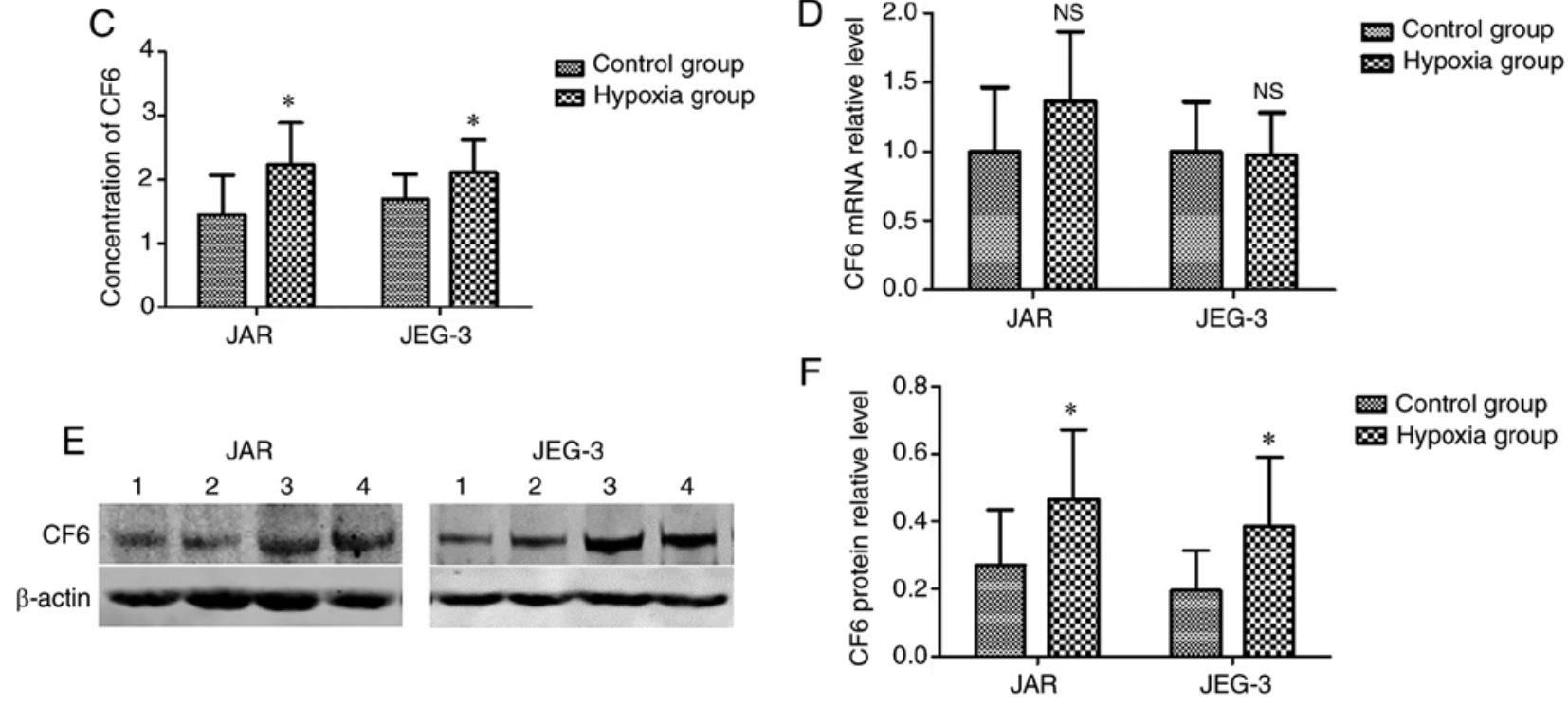

Figure 2. Expression of HIF-1 $\alpha$ and CF6 in trophoblast cells under hypoxia. (A) Western blot analysis of HIF-1 $\alpha$ protein expression after cells were incubated with $200 \mu \mathrm{M} \mathrm{CoCl} 2$ for $24 \mathrm{~h}$ (lanes 1 and 2, control group; 3 and 4, hypoxia group). $\beta$-actin was used as a loading control. (B) HIF-1 $\alpha$ protein expression was significantly increased under hypoxia, indicating that the hypoxic cell models had been successfully established. (C) Quantification of CF6 levels in the two cell lines as determined via ELISA. (D) CF6 mRNA expression levels in the control and hypoxia groups. (E) Western blot analysis of CF6 protein expression (lanes 1 and 2, control group; 3 and 4, hypoxia group). $\beta$-actin was used as a loading control. (F) CF6 protein expression was significantly increased under hypoxia. The experiments were repeated at least three times. "P<0.05 vs. control. CF6, coupling factor 6; HIF-1 $\alpha$, hypoxia-inducible factor $1 \alpha$; NS, not significant.

collected. ELISAs were used for the detection of CF6 concentrations in the culture medium. It was found that the secretion of CF6 was increased in the medium from the hypoxic cells (Fig. 2C). Western blotting was used for the detection of the CF6 protein expression levels, which were found to be significantly increased in the hypoxia group compared with in the control group (Fig. 2E and F). However, RT-qPCR assays did not reveal significant changes in CF6 mRNA expression levels between cells cultured under hypoxic and normal conditions (Fig. 2D).

In vitro exogenous CF6 application decreases the invasive abilities of JAR and JEG-3 cells. Exogenous CF6 was used at a concentration of $0.1 \mu \mathrm{M}$ in the subsequent experiments 
A
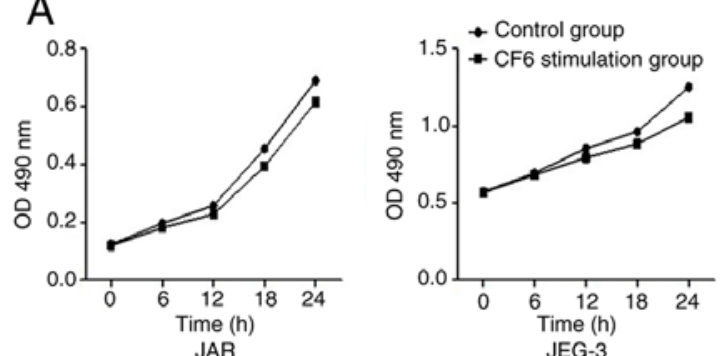

B

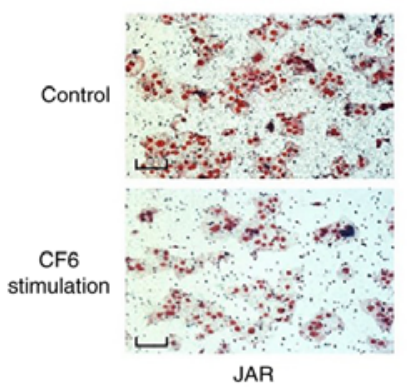

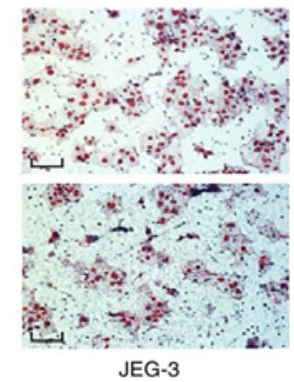
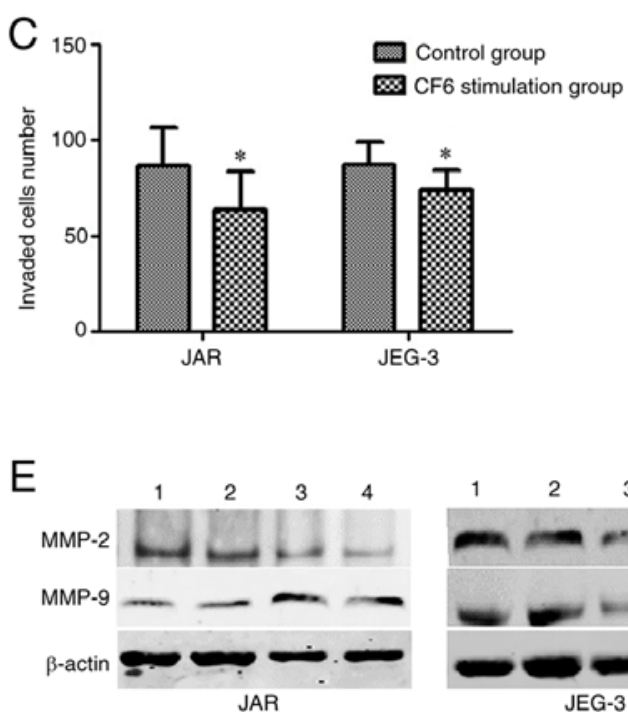

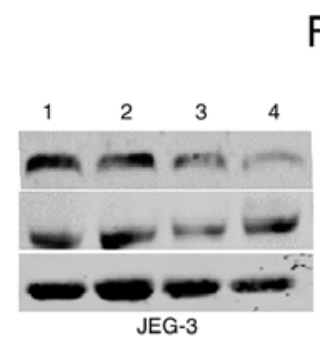

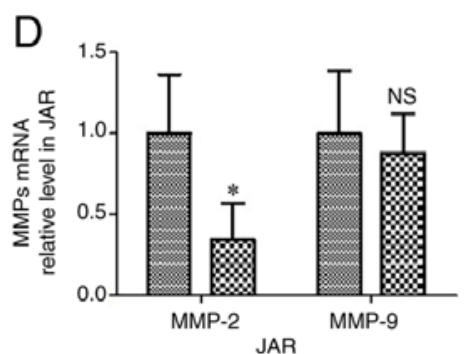

$\mathrm{F}$

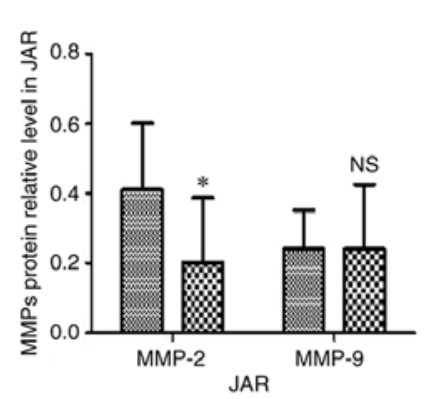

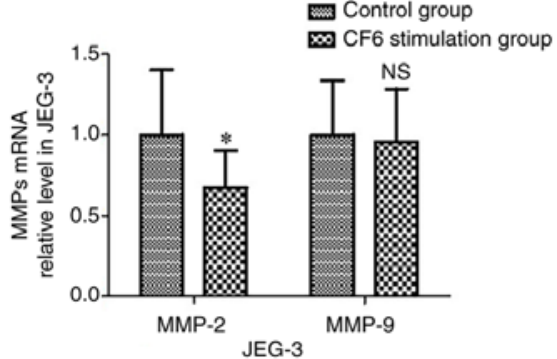

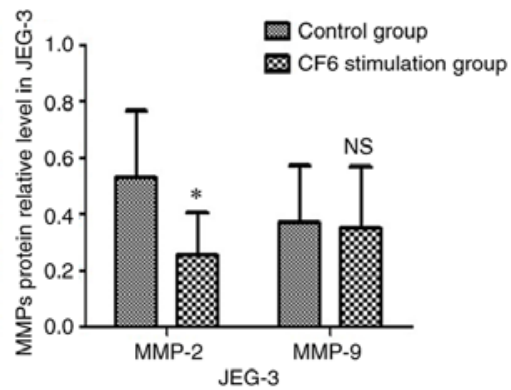

Figure 3. Proliferation and invasion of JAR and JEG-3 cells under exogenous CF6 stimulation. (A) Proliferative activities of the two cell lines; no significant differences between the control and CF6 stimulation groups were observed. (B) Invasion of JAR and JEG-3 cells was measured via Transwell assay (magnification x 400; scale bar, $40 \mathrm{~mm}$ ). (C) Quantitative analysis of the number of invaded cells. (D) MMP-2 and MMP-9 mRNA levels following 24 h of incubation with exogenous CF6. (E) Western blot analysis of MMP-2 and MMP-9 protein expression (lanes 1 and 2, control group; 3 and 4 , CF6 stimulation group). $\beta$-actin was used as a loading control. (F) MMP-2 protein expression was significantly decreased following CF6 stimulation. The experiments were repeated at least three times. ${ }^{*} \mathrm{P}<0.05$ vs. control. CF6, coupling factor 6 ; NS, not significant; OD, optical density.

based on a previous study (11). Furthermore, to detect the proliferative rate of JAR and JEG-3 cells, an MTT assay was employed. No statistical difference was established between the group treated with CF6 and the corresponding control group (Fig. 3A). Accordingly, Transwell assays were utilized to explore the function of CF6 on the invasive capabilities of JAR and JEG-3 cells following incubation with $0.1 \mu \mathrm{M}$ CF6 for $24 \mathrm{~h}$. The results indicated that the two cell types exhibited reduced invasive abilities following treatment with exogenous CF6 $(0.1 \mu \mathrm{M})$ compared with the control group (Fig. 3B and C).

Exogenous CF6 decreases MMP-2 expression levels in JAR and JEG-3 cells. MMP-2 and MMP-9 are considered to be molecular biomarkers of cells with a high invasive capability (14). Therefore, the present study used these two markers to investigate changes in JAR and JEG-3 invasive abilities at the molecular level. RT-qPCR and western blot assays were used to detect MMP mRNA and protein expression levels, respectively. The results indicated that CF6 stimulation decreased the expression levels of both MMP-2 mRNA and protein compared with the control group (Fig. 3D-F). However, neither MMP-9 mRNA levels nor MMP-9 protein levels were altered in the CF6 stimulation group compared with those noted in the control group (Fig. 3D-F).

\section{Discussion}

The present study detected the location and expression levels of CF6 using VCT and EVCT placental TMAs, which provided high-throughput detection, eliminating the variability that has been observed in the immunostaining experiments from different batches (15). It was observed that $\mathrm{CF} 6$ exhibited higher expression levels in preeclamptic placentas compared with that in the normal placentas. Nevertheless, the expression levels of CF6 in the placenta, to the best of our knowledge, have not been previously investigated and no related data are currently available to make comparisons with the present results. Based on the aforementioned findings, two human choriocarcinoma cell lines, namely JAR and JEG-3, were used as experimental tools to examine CF6 expression. The biological characteristics of the two cell lines were shown to be similar to those of normal trophoblast cells (16) and were used to explore the influence of hypoxia on CF6 expression and its release from 
the cells, as well as the effect of CF6 on cell viability and invasion. Based on a previous study, a $\mathrm{CoCl}_{2}$ solution $(200 \mu \mathrm{M})$ was used to establish a hypoxic cell model (17). $\mathrm{CoCl}_{2}$ blocks oxygen signal transduction pathways in cells, which simulates a low-oxygen or hypoxic cellular environment (17). A limitation of the present study is that the effects of this model on cell migration were not investigated. Under hypoxic conditions, the concentration of CF6 in the culture medium was significantly increased. However, the mRNA expression levels of CF6 did not display a significant change. Subsequently, the trophoblast cells were cultured in the medium with exogenous CF6, which decreased cell invasion. Presumably, these aforementioned changes were associated with the observed changes in MMP-2 expression levels.

A number of studies have examined cardiomyopathy under ischemic and/or hypoxic conditions $(13,15,18)$. These studies revealed that the secretion of CF6 increases gradually with prolonged hypoxia and ischemia $(13,15,18)$. In addition, previous pathological examinations of preeclamptic placentas indicated that trophoblast cells that are cultured in a hypoxic environment exhibit a reduced invasive capacity (1).

In animal models of myocardial ischemia, the induction of arterial and left ventricular cell apoptosis in SHR rats has been shown to be higher than that noted in WKY normal rats (19). The CF6 levels in the blood are also increased. Furthermore, high expression levels of CF6 mRNA are also present in SHR rats and left ventricular and arterial cells (19). Concomitantly, the mRNA expression levels of the ATP synthase subunits in myocardial tissue are significantly higher compared with those observed in normal cells (19). This phenomenon indicates that the increased release of CF6 in the hypoxic environment is not only caused by cell death. Hypoxia may induce CF6 overexpression by regulating a signal transduction pathway and stimulating its release into the blood, thus causing a series of downstream physiological changes $(10,19)$. This previous finding appears to differ from the results derived from the present cell experiments. The reason for this difference may be related to the different subjects or organs being tested. Perhaps the expression of CF6 is regulated differently in different tissues. In the present study, the experiments indicated that a decrease in oxygen partial pressure may not affect the transcription of the CF6 gene. However, it can influence the cell metabolism by enhancing the CF6 protein translation.

In addition, the exogenous CF6 levels in the culture medium following treatment with a concentration of $0.1 \mu \mathrm{M}$ CF6 attenuated cell invasion but had no effect on cell proliferation. Previous studies have demonstrated that MMP-2 and MMP-9 are relevant to cell invasion and their expression levels can be used as evaluation index of cell invasion at the molecular level $(14,20)$. Therefore, the present study selected these two factors as cell invasion markers. The mRNA and protein expression levels of the MMP enzymes were measured. The results revealed that $\mathrm{CF} 6$ may affect both the transcription and translation of MMP-2, but not that of MMP-9. These experimental results confirmed that exogenous CF6 reduced the cell invasive abilities by interacting with signal transduction pathways that function upstream of MMP-2 but not MMP-9. Previous studies have shown that the expression of MMP-2 in placental tissues during early pregnancy is significantly increased compared with that of MMP-9 (20-22). MMP-2 can be activated through the PKC-MAPK pathway (20), while the research of Osanai et al (19) shows that the downstream regulation of CF6 is also associated with this pathway $(19,23)$. However, the specific pathways that are modified require further study.

CF6 is one of the subunits forming the $\mathrm{F}_{0} \mathrm{~F}_{1}$-ATP synthase, coded by the nuclear gene ATP5J (23). As an essential part of ATP synthase, CF6 is involved in the synthesis of ATP and therefore, in its absence, the ATP synthase cannot complete the general energy conversion process (23). Currently, to the best of our knowledge, there are no previous studies that have examined CF6 in trophoblast cells, and there is no clear data that shows altered expression of CF6 between the cytoplasm and plasma membrane. Previous studies have found that under certain conditions, such as increased fluid shear force, hypoxia or hyperglycemia, CF6 can be secreted from the plasma membrane into the extracellular fluid. This recognizes and binds with ATP synthase $\beta$ subunits on the plasma membrane, inducing cell metabolism and biological reactions, such as cell migration, invasion and apoptosis, by triggering downstream signaling pathways $(10,24)$. However, it is still unknown which signaling pathways are triggered and whether the functions of CF6 in cytoplasm are through the same mechanism of action; therefore further studies are needed.

Previous studies on HUVECs by Osanai et al (10) and Tomita et al (24) indicated that the production and release of CF6 are mediated by the NF- $\mathrm{B}$ pathway (23) This was confirmed in these studies by an increase in fluid shear stress and a decrease in the protein expression levels of peroxisome proliferator-activated receptor $\gamma$. Sasaki et al (25) further verified that an increase in TNF- $\alpha$ levels can promote the release of CF6 from the cells via the same pathway. A previous study demonstrated that distinct from the mechanisms of TNF- $\alpha$ and fluid shear stress, a high blood glucose concentration can induce CF6 release by activating the PKC-P38MAPK intracellular signal transduction pathway (26). CF6 is released from the cell, enters the blood circulation and binds to the $\beta$-subunit of the ATP synthase in the plasma membrane, which is different from the original function of CF6 (peripheral stalk), which was a part of the structural stem of mitochondrial ATP synthase, involved in the formation and hydrolysis of ATP (2). This type of interaction enhances the hydrolysis of ATP and prompts the $\mathrm{F} 0$-subunit to rotate, pumping $\mathrm{H}^{+}$into the cell and leading to intracellular acidosis (2). In addition, vasodilatation occurs following the decrease in the synthesis of prostacyclin $\left(\mathrm{PGI}_{2}\right)$ through the inhibition of phospholipase A2 (19) and the enhancement of ADMA (dimethylarginine asymmetry) in the acid environment (11). Moreover, the expression of certain molecules contributing to atherosclerosis (phospholipase A2 and ADMA) increases as a result of the raised expression of CF6, aggravating the injury to blood vessels $(11,27,28)$.

The present study revealed that CF6 was overexpressed in the preeclamptic placental tissues and that it could be one of the factors generated and released from the placenta. Moreover, when the preeclamptic placental tissues are exposed to hypoxic and ischemic conditions for an extended period of time, this stimulates the secretion of CF6 from the trophoblasts into the peripheral blood circulation $(6,9)$. 
Subsequently, CF6 binds to the $\beta$-subunit of ATPase on the endothelial cell membranes, activating various downstream signaling factors, such as the release of nitric oxide, the synthesis of $\mathrm{PGI}_{2}$, and the generation and release of soluble fms-like tyrosine kinase 1 (29). This leads to disruption of vascular activity. In the peripheral blood of patients with preeclampsia, the levels of all these factors are changed, which likely contributes to the pathogenesis behind the disease (9). In addition, the current study found that CF6 secreted from the trophoblast cells may have weakened the ability of the cells to invade the surrounding tissues, which was aggravated by the hypoxic conditions of the placental microenvironment. However, in the present study, appropriate experiments were not conducted to clarify whether relevant receptors were expressed in the trophoblast cells, such as the $\beta$-subunit of the ATPase enzyme. Further experiments are required in the future to clarify this hypothesis.

The present study revealed that increase expression levels of CF6 in preeclampsia placenta tissue, especially in severe preeclampsia. Hypoxia increased the secretion of CF6 and high concentrations of CF6 in the extracellular fluid decreased cell invasion which lead to the lack of uterine spiral arteriolar recasting. This may aggravate placental hypoxia, leading to the occurrence of preeclampsia. However, the exact mechanism of action via which CF6 is produced under hypoxic conditions and the method through which the downstream signal peptide is activated remains unclear, which provides a new direction for further research.

\section{Acknowledgements}

Not applicable.

\section{Funding}

Medical Science and Technology Tackle Project of Henan Provincial Health Commission 2019 (Provincial and Ministry Joint Construction Project; grant no. SB201901087).

\section{Availability of data and materials}

The datasets used and/or analyzed during the current study are available from the corresponding author on reasonable request.

\section{Authors' contributions}

WS and HW carried out the experiments, participated in collecting data and drafted the manuscript. KL and XS performed the statistical analysis and participated in the study design. RL, LN and LS participated in acquisition, analysis and interpretation of data, as well as helping with drafting the manuscript. All authors read and approved the final manuscript. WS and HW confirm the authenticity of all the raw data.

\section{Ethics approval and consent to participate}

The study was approved by the Ethics committee of Henan Provincial People's Hospital and the Ethics committee of the Third Affiliated Hospital of the Zhengzhou University. The patients agreed to the use of their samples and each patient signed an informed consent form.

\section{Patient consent for publication}

Not applicable.

\section{Competing interests}

The authors declare that they have no competing interests.

\section{References}

1. Chaiworapongsa T, Chaemsaithong P, Yeo L and Romero R: Pre-eclampsia part 1: Current understanding of its pathophysiology. Nat Rev Nephrol 10: 466-480, 2014.

2. Osanai T, Magota K, Tanaka M, Shimada M, Murakami R, Sasaki S, Tomita H, Maeda N and Okumura K: Intracellular signaling for vasoconstrictor coupling factor 6: Novel function of beta-subunit of ATP synthase as receptor. Hypertension 46: 1140-1146, 2005.

3. Goldman-Wohl DS and Yagel S: Examination of distinct fetal and maternal molecular pathways suggests a mechanism for the development of preeclampsia. J Reprod Immunol 76: 54-60, 2007.

4. Rattila S, Dunk CEE, Im M, Grichenko O, Zhou Y, Yanez-Mo M, Blois SM, Yamada KM, Erez O, Gomez-Lopez N, et al: Interaction of pregnancy-specific glycoprotein 1 with integrin A5 $\beta 1$ is a modulator of extravillous trophoblast functions. Cells 8: 1369, 2019.

5. Osanai T, Magota $\mathrm{K}$ and Okumura K: Coupling factor 6 as a novel vasoactive and proatherogenic peptide in vascular endothelial cells. Naunyn Schmiedebergs Arch Pharmacol 380: 205-214, 2009.

6. Wang JR, Zuo H, Han XY and Yin G: Study on changes of coupling factor 6 in pregnancy induced hypertension. Maternal Child Health Care China 20: 2659-2660, 2005 (In Chinese).

7. Zhu H, Chen L, Zhou W, Huang Z, Hu J, Dai S, Wang X, Huang X and He C: Over-expression of the ATP5J gene correlates with cell migration and 5-fluorouracil sensitivity in colorectal cancer. PLoS One 8: e76846, 2013.

8. Zhang Z, Zhang L, Yang X, Li Y and Duan Z: Construction and validation of a placental tissue microarray from specimens of well-documented preeclampsia patients. Placenta 34: 187-192, 2013.

9. ACOG Committee on Practice Bulletins-Obstetrics: ACOG practice bulletin. Diagnosis and management of preeclampsia and eclampsia. Number 33, January 2002. Obstet Gynecol 99: 159-167, 2002

10. Osanai T, Tanaka M,Kamada T, Nakano T, Takahashi K, Okada S, Sirato K, Magota K, Kodama S and Okumura K: Mitochondrial coupling factor 6 as a potent endogenous vasoconstrictor. J Clin Invest 108: 1023-1030, 2001.

11. Tanaka M, Osanai T, Murakami R, Sasaki S, Tomita H, Maeda N, Satoh K, Magota K and Okumura K: Effect of vasoconstrictor coupling factor 6 on gene expression profile in human vascular endothelial cells: Enhanced release of asymmetric dimethylarginine. J Hypertens 24: 489-497, 2006.

12. Livak KJ and Schmittgen TD: Analysis of relative gene expression data using real-time quantitative PCR and the 2(-Delta Delta C(T)) method. Methods 25: 402-408, 2001.

13. Moser TL, Stack MS, Asplin I, Enghild JJ, Hojrup P, Everitt L, Hubchak S, Schnaper HW and Pizzo SV: Angiostatin binds ATP synthase on the surface of human endothelial cells. Proc Natl Acad Sci USA 96: 2811-2816, 1999.

14. Cui N, Hu M and Khalil RA: Biochemical and biological attributes of matrix metalloproteinases. Prog Mol Biol Transl Sci 147: 1-73, 2017.

15. Zhang L, Li Y, Yang X and Zhang Z: Detection of phosphorylated signal transducer and activator of transcription 3 in extravillous trophoblast cells of preeclampsia by placental tissue microarray. Chin J Perinatal Med 16: 479-484, 2013

16. Bilban M, Tauber S, Haslinger P, Pollheimer J, Saleh L, Pehamberger $\mathrm{H}$, Wagner $\mathrm{O}$ and Knöfler $\mathrm{M}$ : Trophoblast invasion: Assessment of cellular models using gene expression signatures. Placenta 31: 989-996, 2010. 
17. Yuan Y,Hilliard G, Ferguson T and Millhorn DE: Cobalt inhibits the interaction between hypoxia-inducible factor-alpha and von Hippel-Lindau protein by direct binding to hypoxia-inducible factor-alpha. J Biol Chem 278: 15911-15916, 2003.

18. Sangawa H, Himeda T, Shibata $\mathrm{H}$ and Higuti T: Gene expression of subunit $\mathrm{c}(\mathrm{P} 1)$, subunit $\mathrm{c}(\mathrm{P} 2)$, and oligomycin sensitivity-conferring protein may play a key role in biogenesis of $\mathrm{H}^{+}$-ATP synthase in various rat tissues. J Biol Chem 272: 6034-6037, 1997.

19. Osanai T, Kamada T, Fujiwara N, Katoh T, Takahashi K, Kimura M, Satoh K, Magota K, Kodama S, Tanaka T and Okumura K: A novel inhibitory effect on prostacyclin synthesis of coupling factor 6 extracted from the heart of spontaneously hypertensive rats. J Biol Chem 273: 31778-31783, 1998.

20. Fingleton B: Matrix metalloproteinases as regulators of inflammatory processes. Biochim Biophys Acta Mol Cell Res 1864: 2036-2042, 2017.

21. Staun-Ram E, Goldman S, Gabarin D and Shalev E: Expression and importance of matrix metalloproteinase 2 and 9 (MMP-2 and -9) in human trophoblast invasion. Reprod Biol Endocrinol 2: 59, 2004.

22. Schafer-Somi S, Ali Aksoy O,Patzl M, Findik M,Erünal-Maral N, Beceriklisoy HB, Polat B and Aslan S: The activity of matrix metalloproteinase-2 and -9 in serum of pregnant and non-pregnant bitches. Reprod Domest Anim 40: 46-50, 2005.

23. Knowles AF, Guillory RJ and Racker E: Partial resolution of the enzymes catalyzing oxidative phosphorylation. XXIV. A factor required for the binding of mitochondrial adenosine triphosphatase to the inner mitochondrial membrane. J Biol Chem 246: 2672-2679, 1971.

24. Tomita H, Osanai T, Toki T, Sasaki S, Maeda N, Murakami R, Magota K, Yasujima M and Okumura K: Troglitazone and 15-deoxy-delta(12,14)-prostaglandin J2 inhibit shear-induced coupling factor 6 release in endothelial cells. Cardiovasc Res 67: $134-141,2005$
25. Sasaki S, Osanai T, Tomita H, Matsunaga T, Magota K and Okumura K: Tumor necrosis factor alpha as an endogenous stimulator for circulating coupling factor 6. Cardiovasc Res 62: 578-586, 2004

26. Li X, Xing S, Zhang L, Xing Q, Yan S, Dai H, You S, Pang Y and Tang C: High glucose promotes the release and expression of novel vasoactive peptide, coupling factor 6 , in human umbilical vein endothelial cells. Peptides 28: 683-690, 2007.

27. Kumagai A, Osanai T, Katoh C, Tanaka M, Tomita H, Morimoto T, Murakami R, Magota K and Okumura K: Coupling factor 6 downregulates platelet endothelial cell adhesion molecule-1 via c-Src activation and acts as a proatherogenic molecule. Atherosclerosis 200: 45-50, 2008.

28. Tzima E, Irani-Tehrani M, Kiosses WB, Dejana E, Schultz DA, Engelhardt B, Cao G, DeLisser H and Schwartz MA: A mechanosensory complex that mediates the endothelial cell response to fluid shear stress. Nature 437: 426-431, 2005.

29. Echizen T, Osanai T, Ashitate T, Yokoyama H, Shibutani S, Tanaka M, Tomita H, Magota K and Okumura K: Upregulation of soluble vascular endothelial growth factor receptor type 1 by endogenous prostacyclin inhibitor coupling factor 6 in vascular endothelial cells: A role of acidosis-induced c-Src activation. Hypertens Res 32: 182-187, 2009.

(i) (-) This work is licensed under a Creative Commons Attribution-NonCommercial-NoDerivatives 4.0 International (CC BY-NC-ND 4.0) License. 